\title{
Imaging Vascular Endothelial Growth Factor (VEGF) Receptors in Turpentine-Induced Sterile Thigh Abscesses with Radiolabeled Single-Chain VEGF
}

\author{
Zoia Levashova ${ }^{1}$, Marina Backer ${ }^{2}$, Joseph M. Backer ${ }^{2}$, and Francis G. Blankenberg ${ }^{1}$ \\ ${ }^{1}$ Department of Radiology/MIPS, School of Medicine, Stanford University, Stanford, California; and ${ }^{2}$ Sibtech, Inc., Brookfield, \\ Connecticut
}

\begin{abstract}
Angiogenesis plays a central role in the pathogenesis of chronic inflammatory disorders. Vascular endothelial growth factor (VEGF) and its receptors are the most important regulators of angiogenesis. We wished to determine whether labeled forms of single-chain VEGF (scVEGF) could be used to image VEGF receptors in a well-characterized model of sterile soft-tissue inflammation induced by intramuscular injection of turpentine. Methods: Anesthetized adult male Swiss-Webster mice received a $20-\mu \mathrm{L}$ intramuscular injection of turpentine into the right thigh. At 4, 7, or $10 \mathrm{~d}$ later, groups of 3-5 mice were injected via the tail vein with $50 \mu \mathrm{g}$ of either scVEGF that had been site specifically labeled with Cy5.5 (scVEGF/Cy) or inactivated scVEGF/ Cy (inVEGF/Cy) and then examined by fluorescence imaging. At $3,4,6,7,9,10$, or $12 \mathrm{~d}$, additional groups of 3-5 mice were injected via the tail vein with $74-111 \mathrm{MBq}$ of 99mTc-scVEGF (or 99mTc-inVEGF) and then examined by SPECT imaging. Results: On days 3 through 10, both forms of scVEGF (scVEGF/Cy and 99mTc-scVEGF) showed significantly higher uptake $(P<0.05)$ in the right (abscessed) thigh than in the contralateral thigh (and higher uptake than the inactivated tracer). Peak uptake occurred on day 7 (3.67 \pm 1.79 [ratio of uptake in abscessed thigh to uptake in normal thigh, mean \pm SD] and $0.72 \pm 0.01$ for scVEGF/Cy and inVEGF/Cy, respectively, and $3.49 \pm 1.22$ and $1.04 \pm 0.41$ for ${ }^{99 m}$ Tc-scVEGF and $99 \mathrm{mTc}$-inVEGF, respectively) and slowly decreased thereafter. Autoradiography revealed peak tracer uptake in the thick irregular angiogenic rim of the abscess cavity on day $9\left(5.83 \times 10^{-7} \pm 9.22 \times 10^{-8}\right.$ and $5.85 \times$ $10^{-8} \pm 5.95 \times 10^{-8}$ percentage injected dose per pixel for ${ }^{99 \mathrm{mTc}} \mathrm{Tc}$ scVEGF and ${ }^{99 m T c-i n V E G F, ~ r e s p e c t i v e l y) ; ~ i n ~ c o m p a r i s o n, ~ a ~ t h i n ~}$ circumscribed rim of uptake was seen with $99 \mathrm{mT}$ T-inVEGF. Immunostaining revealed that VEGFR-2 (VEGF receptor) colocalized with CD31 (endothelial cell marker) at all time points in the abscess rim, whereas F4/80 (macrophage) immunostaining reached a maximum at day 7 and decreased by day 10 . Conclusion: The uptake of scVEGF in turpentine-induced abscesses was specific and directly related to VEGFR-2 expression in the neovasculature of the angiogenic rim. Peak tracer uptake coincided with maximum macrophage infiltration, suggesting
\end{abstract}

Received Jul. 6, 2009; revision accepted Aug. 20, 2009.

For correspondence or reprints contact: Francis G. Blankenberg, Lucile Salter Packard Children's Hospital at Stanford, 725 Welch Rd.,

Room 1673, Stanford, CA 94304-1601.

E-mail: blankenb@stanford.edu

COPYRIGHT @ 2009 by the Society of Nuclear Medicine, Inc. that scVEGF imaging may be useful for the detection, localization, and monitoring of chronic inflammation in bone, joints, or soft tissues.

Key Words: angiogenesis; VEGF; SPECT; inflammation; musculoskeletal system

J Nucl Med 2009; 50:2058-2063

DOI: 10.2967/jnumed.109.068023

A lthough angiogenesis is now widely accepted as an integral component of solid tumor growth and the development of metastases, its contribution to the pathophysiology of chronic inflammation has largely been unexplored (1-4). Chronic inflammation is characterized by the infiltration of macrophages into organizing fibrotic-hypervascular tissue that surrounds sites of disease (5). More recent investigations have shown that macrophages and angiogenic endothelial cells express high levels of monocyte chemoattractant peptide 1, vascular endothelial growth factor (VEGF), and VEGF receptors; these findings suggested that these cell types work with each other to generate and maintain chronic inflammation in a variety of disorders, including bacterial, fungal, and viral infections, rheumatologic and autoimmune disorders, atherosclerosis, organ transplant rejection, and cancer (6-8). A noninvasive method for assessing the presence, location(s), extent, and intensity of increased VEGF receptor expression would be of clinical value, particularly in chronic joint and soft-tissue infections, which are notoriously difficult to detect with standard markers (such as gallium, ${ }^{18}$ F-FDG [with PET], and radiolabeled white blood cells) (9-11). Serial imaging of VEGF receptor expression could also be quite helpful in guiding biologic modifier therapy for common chronic noninfectious inflammatory disorders (such as rheumatoid arthritis, inflammatory bowel disease, and multiple sclerosis), for which annual drug costs alone can be as high as \$10,000-\$50,000 (12-14). 
Previously we developed a family of tracers for the imaging of VEGF receptors present in angiogenic vasculature with several different modalities $(15,16)$. These tracers are based on engineered single-chain VEGF (scVEGF), composed of 2 fused 3- to 112-amino-acid fragments of VEGF $_{121}$ and an N-terminal 15-amino-acid Cys tag containing a unique cysteine residue for the site-specific attachment of a variety of agents (17). scVEGF-based tracers bind to and are internalized by VEGF receptors, providing information on the prevalence and distribution of active regions of ongoing angiogenesis in vivo.

In this study, our aim was to determine whether fluorescence-labeled and ${ }^{99 \mathrm{~m}} \mathrm{Tc}$-radiolabeled scVEGF-based tracers could be used to image VEGF receptors in a welldescribed region of sterile inflammation induced by intramuscular injection of turpentine (18). The advantages of this model include the lack of systemic illness and hypotension (sepsis), the recapitulation of all phases of abscess formation (i.e., acute, subacute, chronic, end-stage fibrosis, and scar formation), and high levels of reproducibility and localization of soft-tissue injury.

\section{MATERIALS AND METHODS}

\section{Animal Model}

The protocols for all of the animal studies were approved by the Stanford University Institutional Animal Care and Use Committee. Male Swiss-Webster mice (5-6 wk old) were purchased from Charles River Laboratories. Mice were anesthetized with an intraperitoneal injection of ketamine $(100 \mathrm{mg} / \mathrm{kg})$ and xylazine $(10 \mathrm{mg} / \mathrm{kg}$ ) before intramuscular injection (via a 28 -gauge needle) of $20 \mu \mathrm{L}$ of turpentine into the posterior-lateral aspect of the right thigh (18).

\section{Production of scVEGF/Cy and inVEGF/Cy}

The construction, expression, and purification of scVEGF were described by Backer et al. (17). scVEGF/Cy, a fluorescent form of scVEGF that had been site specifically labeled with Cy5.5 (GE Healthcare) or Alexa-594 (Molecular Probes), was produced by SibTech, Inc. Inactivated forms of scVEGF and scVEGF/Cy (inVEGF and inVEGF/Cy, respectively), which were incapable of binding to VEGF receptors, were also produced by SibTech.

\section{Fluorescence Imaging}

At 4,7 , or $10 \mathrm{~d}$ after turpentine treatment, groups of 3-5 mice were injected via the tail vein with $50 \mu \mathrm{g}$ of either scVEGF/Cy or inVEGF/Cy. Two hours later, the mice were imaged with an eXplore Optix system (Advanced Research Technologies Inc.). Acquired images were analyzed with software from Optiview, Inc.

\section{Preparation of ${ }^{99 m}$ Tc-Radiolabeled scVEGF}

Deprotected scVEGF and inVEGF were radiolabeled with ${ }^{99 \mathrm{~m} T c-t r i c i n e}$ as a precursor complex (19). Lyophilized tin-tricine reagent was reconstituted with $0.25 \mathrm{~mL}$ of degassed saline to produce a final $\mathrm{SnCl}_{2} \cdot 2 \mathrm{H}_{2} \mathrm{O}$ concentration of $3 \mathrm{mg} / \mathrm{mL}$ and a final tricine concentration of $100 \mathrm{mg} / \mathrm{mL}(\mathrm{pH} \mathrm{7.1)}$ as described previously (16). Tin-tricine $(2.5-5.0 \mu \mathrm{L})$ was mixed with $30-50 \mu \mathrm{g}$ of deprotected scVEGF (or inVEGF) and 370-740 MBq of ${ }^{99 \mathrm{~m}} \mathrm{Tc}-$ pertechnetate in a final volume of $50-100 \mu \mathrm{L}$. After $30 \mathrm{~min}$ of incubation at $37^{\circ} \mathrm{C}$, the radiolabeled protein $\left({ }^{99 \mathrm{~m}} \mathrm{Tc}-\mathrm{scVEGF}\right.$ or
${ }^{99 m}$ Tc-inVEGF) was purified by gel filtration with PD-10 Sephadex-25 columns (Amersham Biosciences).

\section{SPECT and 3-Dimensional (3D) Statistical Analyses}

For SPECT, 74-111 MBq of tracer per mouse was injected via the tail vein into groups of $3-5$ mice at $3,4,6,7,9,10$, or $12 \mathrm{~d}$ after turpentine treatment. At $2 \mathrm{~h}$ after tracer injection, mice were anesthetized with an intraperitoneal injection of ketamine (100 $\mathrm{mg} / \mathrm{kg})$ and xylazine $(10 \mathrm{mg} / \mathrm{kg})$. SPECT was performed with a small-animal single-head SPECT $\gamma$-camera (A-SPECT, LumaGEM; Gamma Medica) and the following parameters: $360^{\circ}$ rotation, 64 steps, $30 \mathrm{~s}$ per step, $0.5-\mathrm{mm}$ pinhole aperture, $64 \times 64$ image matrix, and $2.7-\mathrm{cm}$ field of view. After imaging was completed, mice were sacrificed via $\mathrm{CO}_{2}$ inhalation for autoradiography and immunohistochemical staining.

\section{Autoradiography and Immunohistochemical Staining}

For autoradiography and immunohistochemical staining, samples of abscesses and normal muscle from the contralateral thigh were snap-frozen, and $20-\mu \mathrm{m}$ tumor cryosections were obtained. For autoradiography, sections were exposed to a phosphor storage screen for $24 \mathrm{~h}$ along with spots of standard activities. The phosphor screen images were read with a laser digitizer (Storm 860; Amersham Biosciences/GE Healthcare) at a resolution of 50-100 $\mu \mathrm{m}$ per pixel. Region-of-interest (ROI) analysis of radiotracer activity was performed with ImageQuant TL software (GE Healthcare). The results were expressed as the percentage injected dose per pixel $(50 \times 50 \mu \mathrm{m})$.

For immunohistochemical analysis, sections were stained for F4/80 (macrophages), VEGFR-2 (VEGF receptor) (Flk-1, rat monoclonal antibody, 1:100 dilution; catalog number 550549 [BD Pharmingen]), and CD31 (PECAM, rat monoclonal antibody, 1:300 dilution; catalog number 550274 [BD Pharmingen]) and developed with a chromogenic VECTASTAIN Elite ABC Kit (catalog number PK-7200; Vector Laboratories, Inc.) and a VIP Substrate Purple Kit (catalog number SK-4100; Vector Laboratories). Digital images were obtained by use of a Zeiss AxioObserver 1 fluorescence microscope with a $\times 40$ oil objective. Individual and merged images were processed with Zeiss software and exported into Adobe Photoshop (Adobe Systems Inc.).

\section{Statistical Analyses}

Volumetric SPECT data underwent 3D statistical analyses by use of parametric 3D ROIs that were interactively placed and sized but that were geometric, as described by Tang et al. (20). ROIs were drawn on samples of abscesses and tissue from the contralateral thigh (background), and the activity in each region was obtained (and expressed as counts per voxel). The ratio of activity in the abscess to background (contralateral) activity, expressed as the integrated counts per voxel from the 50th percentile to the 67 th percentile for each animal, was then tabulated.

All values were expressed as the mean $\pm 1 \mathrm{SD}$. The Student 2 -tailed $t$ test with unequal variances ( 2 samples) was used for statistical comparisons of normal and diseased thighs as well as of scVEGF and inVEGF forms of labeled protein. A $P$ value of 0.05 or less was considered to be significant. 


\section{RESULTS}

\section{Optical Imaging with scVEGF/Cy}

Significantly greater uptake of scVEGF/Cy than of inVEGF/Cy was seen at 4, 7, and $10 \mathrm{~d}$ after injection of turpentine into the right thigh (Fig. 1A). Little to no increased uptake of inVEGF/Cy in the right thigh was noted at all time points relative to uptake in the contralateral (left; control) thigh, as confirmed by ROI analysis (Fig. 1B). Focal increased uptake of scVEGF/Cy in abscesses therefore appeared to be specific and unrelated to increases in capillary permeability or regional blood flow. Peak tracer uptake occurred on day 7 , with values of $3.67 \pm 1.79(n=3)$ and $0.72 \pm 0.01(n=3)(P=0.046)$ for scVEGF/Cy and inVEGF/Cy, respectively. Significantly greater uptake of scVEGF/Cy than of inVEGF/Cy in abscesses was seen on days 4 and 10 as well, with values of $2.17 \pm 0.55(n=5$; $P=0.0036)$ on day 4 and $2.40 \pm 1.21(n=5 ; P=0446)$ on day 10 ; the values for inVEGF/Cy were $0.97 \pm 0.082$ $(n=4)$ and $0.091 \pm 0.35(n=3)$, respectively. After $10 \mathrm{~d}$, the uptake of scVEGF/Cy in abscesses decreased to that seen with inVEGF/Cy imaging.

Analyses of frozen histologic sections demonstrated that scVEGF/Cy colocalized with the increased expression of VEGFR-2 in the inflammatory angiogenic rim surrounding the abscess cavity (Fig. 2).

FIGURE 1. ScVEGF/Cy imaging of sterile right thigh abscesses. (A) ROls were drawn over right and left thighs (without shaving), and images were obtained at pixel size of $1 \times 1 \mathrm{~mm}$ with eXplore Optix fluorescence imaging system (scan time, $\sim 20$ min). Markedly higher signal intensity was seen in right (abscessed) thigh than in left (control) thigh on days $4(4 \mathrm{~d}), 7(7 \mathrm{~d})$, and 10 (10 d). Uptake of inVEGF/Cy in right thigh was lower than that of scVEGF/Cy at same time points; in addition, signal intensity of inVEGF/Cy in right thigh was never significantly greater than that in left thigh. (B) Corresponding ROI data from fluorescence imaging with scVEGF/Cy and inVEGF/Cy. Error bars represent 1 SD from mean, expressed as ratio of right thigh $\mathrm{ROI}$ integrated signal intensity to left thigh ROI integrated signal intensity. For right thigh imaged with scVEGF/Cy vs. inVEGF/Cy, $P$ values were as follows: ${ }^{\star} P<0.05$; ${ }^{\star \star} P<0.001$. Values in parentheses represent number of mice imaged with scVEGF/Cy/number of mice imaged with inVEGF/Cy at each time point. $\mathrm{NS}=$ not significant.

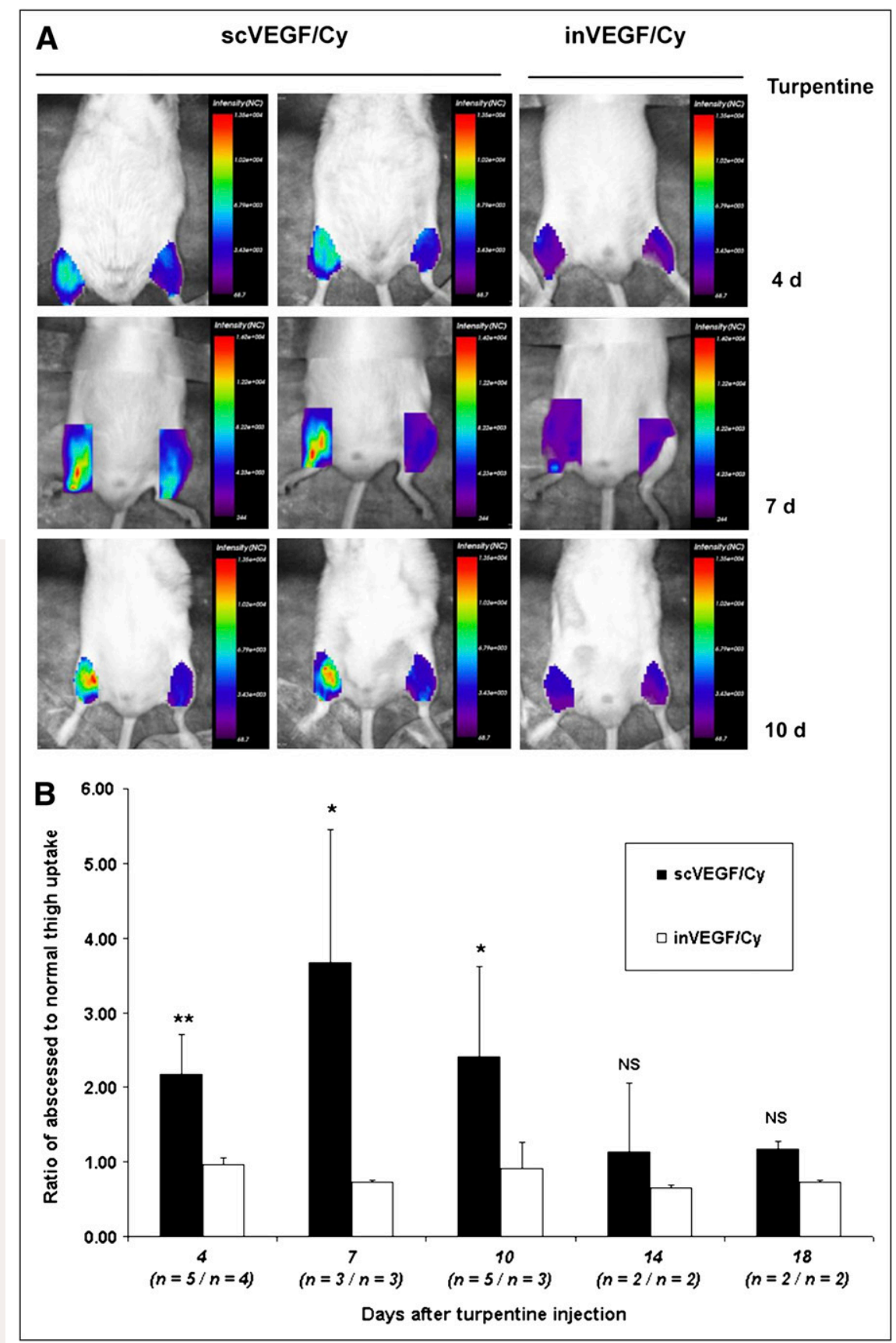




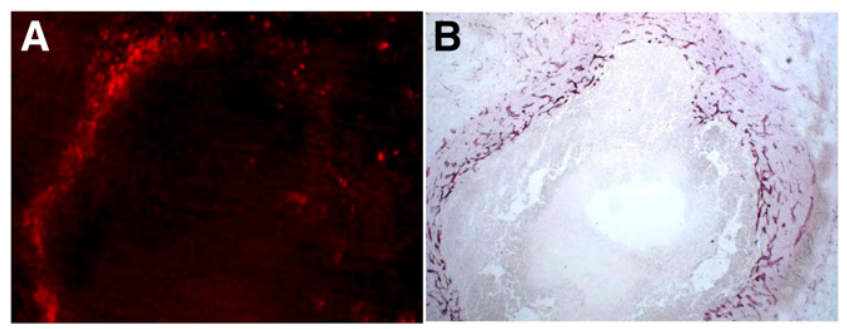

FIGURE 2. ScVEGF-Alexa-594 colocalizes with VEGFR-2 expression, as revealed by immunohistochemical (IHC) staining. (A) Fluorescence microscopy of scVEGF-Alexa594 at $\times 10$. (B) VEGFR-2 IHC staining performed after fluorescence microscopy of histologic section shown in $A$, also at $\times 10$. IHC staining and fluorescence microscopy confirmed specific colocalization of fluorophor-labeled scVEGF and VEGFR-2 in angiogenic rim of each abscess.

\section{Radionuclide Imaging with $99 \mathrm{~m}$ Tc-scVEGF}

99mTc-scVEGF with specific activities ranging from approximately 4.8 to $7.4 \mathrm{MBq}$ per microgram of protein and with radiopurities of $90 \%-95 \%$ (as determined by instant thin-layer chromatography with phosphate-buffered saline as a solvent) was used for SPECT and autoradiographic imaging. The uptake of ${ }^{99} \mathrm{~m}$ Tc-scVEGF in the right thigh was significantly greater than that of ${ }^{99 \mathrm{~m} T c-i n V E G F}$ at all time points, as confirmed by both SPECT and autoradiography (Fig. 3). ${ }^{99 m}$ Tc-inVEGF imaging demonstrated clearly visible diffuse bone marrow activity at day 7 ,

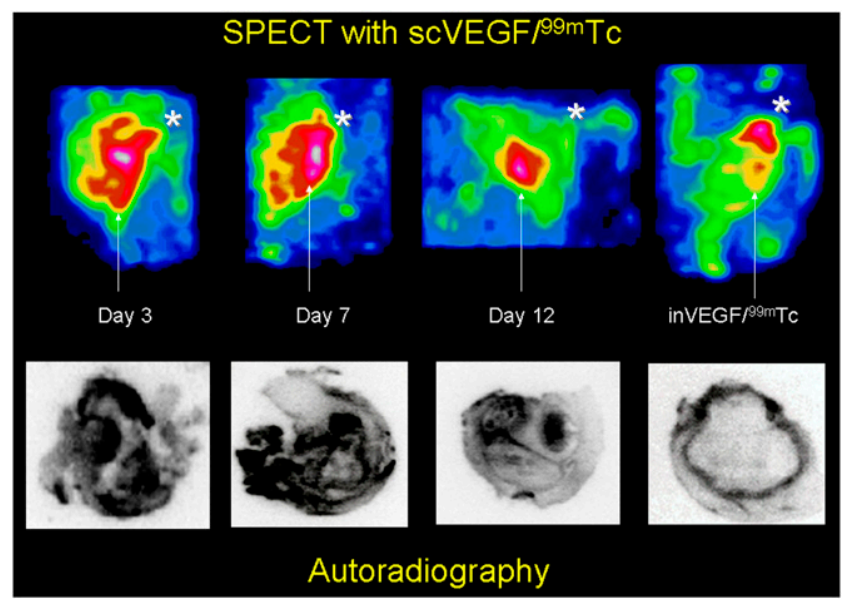

FIGURE 3. ${ }^{99 m T C-s c V E G F ~ S P E C T ~ o f ~ s t e r i l e ~ r i g h t ~ t h i g h ~}$ abscesses. Top row of images shows reconstructed 3D views of right thigh in anterior oblique projection. Arrows indicate inferior edge of right thigh abscesses; asterisks indicate location of right knee joint. Marked uptake of $99 \mathrm{mTc}-$ scVEGF centered at location of right thigh abscess on days 3 and 7 decreased on day 12. Image at far right is SPECT image of uptake of ${ }^{99 m}$ Tc-inVEGF on day 7 after turpentine injection. Minimal blood-pool activity in right thigh abscess was significantly lower than nonspecific right knee metaphyseal and bone marrow uptake of tracer. Bottom row of images shows corresponding autoradiographs of $20-\mu \mathrm{m}$ histologic sections. with nonspecific pooling of the tracer in the metaphyseal regions around the knee and other joints in all mice (Fig. 3, image at far right).

Peak tracer uptake was observed on days 7 and 9 in SPECT and autoradiographic analyses (Figs. 4A and 4B, respectively). SPECT ROI analyses demonstrated a fold increase of $3.49 \pm 1.22(n=4)$ in ${ }^{99 m}$ Tc-scVEGF uptake in the abscessed thigh over that in the contralateral (normal) thigh or ${ }^{99 m}$ Tc-inVEGF uptake $(1.04 \pm 0.41 ; n=4)$ in the right thigh $(P=0.009)$. ROI analyses of autoradiographs revealed striking heterogeneous uptake of ${ }^{99 \mathrm{~m}} \mathrm{Tc}-\mathrm{scVEGF}$ in a thick irregular abscess rim on days 7 and 9. The percentage injected doses per pixel were $4.98 \times 10^{-7} \pm$ $7.88 \times 10^{-8}(n=4)$ on day 7 and $5.83 \times 10^{-7} \pm 9.22 \times$ $10^{-8}(n=4)$ on day 9 ; these percentage injected doses per pixel were significantly greater $(P<0.001)$ than that for ${ }^{99 m}$ Tc-inVEGF $\left(5.85 \times 10^{-8} \pm 5.95 \times 10^{-8} ; n=4\right.$, subgroup of mice from days $4,7,9$, or 10 ). In comparison, the uptake of ${ }^{99 m}$ Tc-inVEGF was seen in a relatively thin rim and was well defined at all time points, probably as a result of nonspecific capillary leak and increased regional blood flow. The uptake of ${ }^{99 \mathrm{~m} T c-s c V E G F}$ remained significantly elevated on days 10 and 12 , with percentage injected doses per pixel of $3.06 \times 10^{-7} \pm 1.8 \times 10^{-7}(n=4)$ on day 10 and $3.71 \times 10^{-7} \pm 2.86 \times 10^{-7}(n=5)$ on day 12 ; however, this uptake was lower than the peak uptake seen on days 7 and 9.

Immunohistochemical staining of frozen tissue sections revealed that the thick abscess rim showed markedly increased VEGFR-2 (Flk-1) expression and CD31 (endothelial cell marker) staining, as shown in Supplemental Figure 1A (supplemental materials are available online only at http:// jnm.snmjournals.org). In addition, the abscess rim appeared to show dense infiltration with macrophages (F4/80). Maximal staining for each marker was observed on day 7 and was visibly reduced by day 10 . Immunofluorescence analysis at a higher magnification revealed that virtually all VEGFR-2 colocalized with CD31, indicating that this receptor is expressed exclusively on endothelial cells (Supplemental Fig. 1B, top row). Interestingly, another VEGF receptor, VEGFR-1, was also detectable at the inflammation site; it mostly, but not always, colocalized with CD31 (Supplemental Fig. 1B, middle and bottom rows).

\section{DISCUSSION}

All current modalities, including MRI, CT, ultrasound, ${ }^{18}$ F-FDG PET, and radiolabeled white blood cell scanning, have significant drawbacks for the screening and monitoring of chronic inflammation in soft tissues, bone, and other organs (9-11). These drawbacks include lack of specificity and sensitivity, cost, and the logistic difficulties associated with the imaging of systemic disease which, more often than not, requires whole-body imaging. Radiolabeled forms of scVEGF, particularly with ${ }^{99 \mathrm{~m}} \mathrm{Tc}$, could offer a costeffective and molecular level-specific methodology for 
FIGURE 4. (A) ROI analysis of $99 \mathrm{mTc}-$ scVEGF in SPECT images of sterile right thigh abscesses. Data are presented as average ratio of uptake in right thigh to that in left thigh (50th-67th percentile for abscessed thigh uptake/50th-67th percentile for control thigh uptake). Error bars $=1 \mathrm{SD}$ from mean. ${ }^{*} P<$ $0.05 ;{ }^{* *} P<0.001$. (B) ROI analysis of $99 \mathrm{mTC}-\mathrm{scVEGF}$ in autoradiographs of thigh abscesses. Data are presented as average percentage injected dose (\%ID) of tracer per $50-\mu \mathrm{m}$ pixel. Error bars $=1 \mathrm{SD}$ from mean. ${ }^{\star *} P<0.001$; ${ }^{\star * \star} P<0.00001$. Values in parentheses represent number of mice in each subgroup.

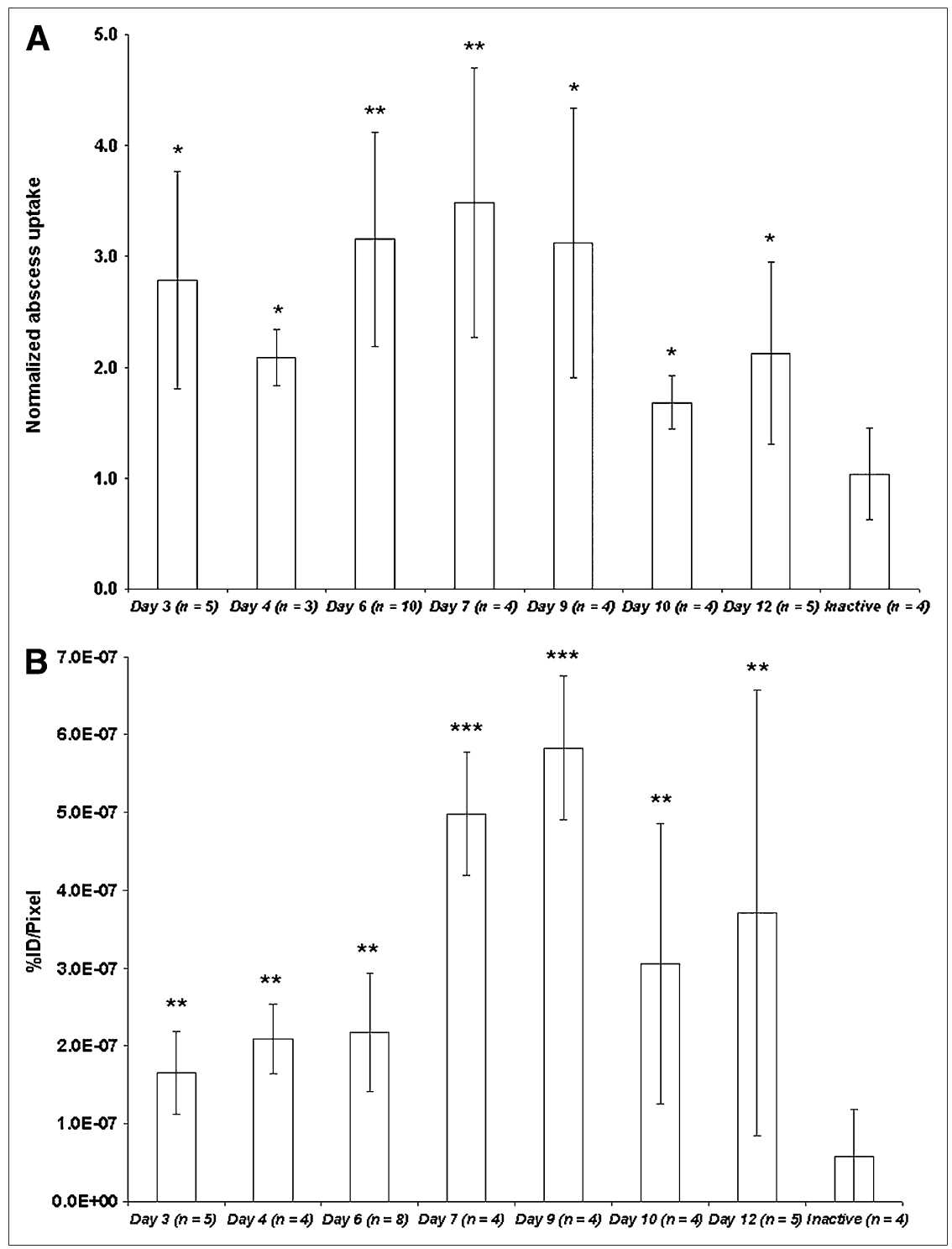

imaging inflammatory angiogenesis, which appears to be a consistent feature of most, if not all, chronic infectious and noninfectious inflammatory musculoskeletal disorders.

The uptake of fluorescent and radiolabeled scVEGFbased tracers in sterile turpentine-induced abscesses in the right thigh in our model was specific and was attributable to the increased expression of VEGFR-2 in the angiogenic vasculature, as indicated by CD31 immunohistochemical staining of endothelial cells. The marked increase in VEGFR-2 expression also coincided with the dense infiltration of monocytes and macrophages; these cells secrete both VEGF and chemotactic factors that are crucial in the pathogenesis of noninfectious subacute and chronic inflammation.

The time course of scVEGF uptake in thigh abscesses correlated well with the known progression of histologic changes observed with turpentine-induced thigh abscesses (18), namely, acute-phase neutrophil infiltration (24-48 h, low scVEGF uptake), macrophage infiltration starting at $72 \mathrm{~h}$ and the beginning of angiogenesis (onset of chronic inflammation), peak macrophage density and vessel formation on days 7-9 (fully developed chronic inflammation), and the development of fibrosis and decreasing numbers of macrophages after day 10 (organization of abscess and scar formation, decreasing scVEGF uptake).

Our results suggested that VEGF receptor imaging of the musculoskeletal system could be useful for detection and assessment of the severity of a variety of common chronic inflammatory disorders in which increased VEGF receptor and VEGF expression plays a crucial role in disease progression. For instance, VEGF is central in the pathogenesis of many types of arthritis, including rheumatoid arthritis, by protecting synoviocytes from apoptosis and thereby contributing to synovial hyperplasia and pannus formation (21). Increased VEGF levels have also been shown to be predictive of joint destruction at least $1 \mathrm{y}$ 
before radiographic progression in a group of 310 patients with polyarthritis (22).

Increased production of VEGF by chondrocytes also plays a key role in the postinfectious destruction of articular cartilage by promoting angiogenesis in the emerging synovial pannus and increasing vascular permeability for neutrophil influx and matrix metalloproteinase activity in a diseased joint even after elimination of the bacterial or fungal pathogen (23). Angiogenesis also is important in the pathophysiology of osteoarthritis, even in the absence of clinical signs of inflammation (24). Angiogenesis in osteoarthritis is caused by high-intensity mechanical stresses on joint chondrocytes which, in turn, increase the production of VEGF and matrix metalloproteinase and thereby cause thinning of the joint cartilage (25). Stressed chondrocytes in the presence of angiogenesis also fail to arrest their maturation, thereby both promoting excessive and inappropriate endochondral ossification and bone formation within the already thinned cartilage and accelerating joint degeneration. These results imply that angiogenesis within a joint reflects disease severity and that evaluation of vascularization may become both a useful tool in the assessment of disease activity for several articular disorders and a target for therapeutic intervention.

\section{CONCLUSION}

We conclude that the uptake of radiolabeled scVEGF directly and specifically reflects the degree of VEGFR-2 expression in vivo. Peak tracer uptake coincided with maximal macrophage infiltration, suggesting that scVEGF imaging may be useful for the detection, localization, and monitoring of chronic inflammation in bone, joints, or soft tissues.

\section{REFERENCES}

1. Carmeliet P. Angiogenesis in health and disease. Nat Med. 2003;9:653-660.

2. Walsh DA. Pathophysiological mechanisms of angiogenesis. Adv Clin Chem. 2007;44:188-212.

3. Halin C, Detmar M. Inflammation, angiogenesis, and lymphangiogenesis. Methods Enzymol. 2008;445:2-20.

4. Roscoe WA, Welsh ME, Carter DE, Karlik SJ. VEGF and angiogenesis in acute and chronic MOG(35-55) peptide induced EAE. J Neuroimmunol. 2009;209: 6-15.

5. Medzhitov R. Origin and physiological roles of inflammation. Nature. 2008;454:428-435.
6. Frantz S, Vincent KA, Feron O, Kelly RA. Innate immunity and angiogenesis. Circ Res. 2005;96:15-26.

7. Costa C, Incio J, Soares R. Angiogenesis and chronic inflammation: cause or consequence? Angiogenesis. 2007;10:149-166.

8. Danese S, Dejana E, Fiocchi C. Immune regulation by microvascular endothelial cells: directing innate and adaptive immunity, coagulation, and inflammation. J Immunol. 2007;178:6017-6022.

9. Prandini N. Nuclear medicine imaging of bone infections. Nucl Med Commun. 2006;27:633-644.

10. El-Maghraby TAF, Moustafa HM, Pauwels EKJ. Nuclear medicine methods for evaluation of skeletal infection among other diagnostic modalities. $Q \mathrm{~J} \mathrm{Nucl} \mathrm{Med}$ Mol Imaging. 2006;50:167-192.

11. Goldsmith SJ, Vallabhajosula S. Clinically proven radiopharmaceuticals for infection imaging: mechanisms and applications. Semin Nucl Med. 2009;39: $2-10$.

12. Graves JE, Nunley K, Heffernan MP. Off-label uses of biologics in dermatology: rituximab, omalizumab, infliximab, etanercept, adalimumab, efalizumab, and alefacept (part 2 of 2). J Am Acad Dermatol. 2007;56:e55-e79.

13. Khanna R, Smith MJ. Utilization and costs of medical services and prescription medications for rheumatoid arthritis among recipients covered by a state Medicaid program: a retrospective, cross-sectional, descriptive, database analysis. Clin Ther. 2007;29:2456-2467.

14. Bickston SJ, Waters HC, Dabbous O, Tang BI, Rahman M. Administrative claims analysis of all-cause annual costs of care and resource utilization by age category for ulcerative colitis patients. J Manag Care Pharm. 2008;14:352-362.

15. Backer MV, Levashova Z, Patel V, et al. Molecular imaging of VEGF receptors in angiogenic vasculature with single-chain VEGF-based probes. Nat Med. 2007;13:504-509.

16. Levashova Z, Backer M, Backer JM, Blankenberg FG. Direct site-specific labeling of the Cys-tag moiety in scVEGF with technetium $99 \mathrm{~m}$. Bioconjug Chem. 2008;19:1049-1054.

17. Backer MV, Levashova Z, Levenson R, Blankenberg FG, Backer JM. Cysteinecontaining fusion tag for site-specific conjugation of therapeutic and imaging agents to targeting proteins. Methods Mol Biol. 2008;494:275-294.

18. Blankenberg FG, Tait JF, Blankenberg TA, Post AM, Strauss HW. Imaging macrophages and the apoptosis of granulocytes in a rodent model of subacute and chronic abscesses with radiolabeled monocyte chemotactic peptide- 1 and annexin V. Eur J Nucl Med. 2001;28:1384-1393.

19. Larsen SK, Solomon HF, Caldwell G, Abrams MJ. [ ${ }^{99 m}$ Tc]tricine: a useful precursor complex for the radiolabeling of hydrazinonicotinate protein conjugates. Bioconjug Chem. 1995;6:635-638.

20. Tang XN, Wang Q, Koike MA, et al. Monitoring the protective effects of minocycline treatment with radiolabeled annexin $\mathrm{V}$ in an experimental model of focal cerebral ischemia. J Nucl Med. 2007;48:1822-1828.

21. Yoo SA, Kwok SK, Kim WU. Proinflammatory role of vascular endothelial growth factor in the pathogenesis of rheumatoid arthritis: prospects for therapeutic intervention. Mediators Inflamm. February 10, 2009 [Epub ahead of print].

22. Clavel G, Bessis N, Lemeiter D, et al. Angiogenesis markers (VEGF, soluble receptor of VEGF and angiopoietin-1) in very early arthritis and their association with inflammation and joint destruction. Clin Immunol. 2007;124:158-164.

23. Varoga D, Paulsen F, Mentlein R, et al. TLR-2-mediated induction of vascular endothelial growth factor (VEGF) in cartilage in septic joint disease. J Pathol. 2006;210:315-324.

24. Bonnet CS, Walsh DA. Osteoarthritis, angiogenesis and inflammation. Rheumatology. 2005;44:7-16.

25. Tanaka E, Aoyama J, Miyauchi M, et al. Vascular endothelial growth factor plays an important autocrine/paracrine role in the progression of osteoarthritis. Histochem Cell Biol. 2005;123:275-281. 